\title{
BEBAN EKONOMI PADA PENDERITA HIPERTENSI DENGAN STATUS PBI JKN DI KABUPATEN PAMEKASAN
}

\author{
Ashri Nur Istiqomah*, Thinni Nurul Rochmah* \\ *Fakultas Kesehatan Masyarakat, Universitas Airlangga, Surabaya \\ Email: ashrinuris@gmail.com
}

\begin{abstract}
ABSTRAK
Hipertensi merupakan salah satu penyakit kronis yang berlangsung secara menahun dan sering kali tidak bisa disembuhkan. Jumlah kasus hipertensi di Kabupaten Pamekasan pada periode 2012-2014 mengalami fluktuasi. Pada tahun 2012 jumah kasus hipertensi sebanyak 22.808 kasus, tahun 2013 sebanyak 19.746 kasus dan tahun 2014 sebanyak 21.908 kasus. Jumlah kasus yang tinggi menyebabkan hipertensi termasuk dalam kategori sepuluh penyakit terbanyak di Kabupaten Pamekasan pada periode tahun 2012-2014. Penelitian ini dilakukan untuk mengetahui beban ekonomi yang ditanggung oleh penderita hipertensi dengan status PBI JKN di Kabupaten Pamekasan. Penelitian ini termasuk dalam penelitian kuantitatif dan observasional. Apabila ditinjau dari waktu, penelitian ini termasuk penelitian cross sectionalPengambilan sampel dilakukan dengan cara purposive sampling. Teknik yang digunakan dalam pengumpulan data primer adalah melalui wawancara kepada 100 responden dengan menggunakan kuesioner untuk mendapatkan informasi yang lebih mendalam tentang variabel yang diteliti. Hasil penelitian menunjukkan bahwa penderita hipertensi dengan status PBI di Kabupaten Pamekasan mulai terdiagnosa hipertensi pada umur 52 tahun dengan nilai DALYs 19. Rata-rata biaya langsung yang dikeluarkan penderita hipertensi dengan status PBI di Kabupaten Pamekasan adalah sebesar Rp157.600,-. Rata-Rata biaya tidak langsung adalah sebesar Rp674.980,-. Kesimpulan yang dapat ditarik adalah biaya tidak langsungyang dikeluarkan penderita hipertensi dengan status PBI di Kabupaten Pamekasan lebih besar dari pada biaya langsung. Sebanyak $65 \%$ responden masih mengeluarkan biaya pelayanan kesehatan. Hal ini membuat beban ekonomi yang ditanggung semakin besar dan masih banyak masyarakat yang belum menyadari bahwa hipertensi yang dialami menyebabkan kerugian ekonomi yang secara tidak langsung juga akan mempengaruhi kesejahteran baik di tingkat rumah tangga, regional maupun nasional.
\end{abstract}

Kata kunci: Beban ekonomi,Hipertensi, PBI JKN

\begin{abstract}
Hypertension is one of the chronic disease that usually can not be recovered. The number of hypertension case in Pamekasan District was fluctuating in 2012-2014. In 2012 hypertension case was 22.808 cases, in 2013 was 19.746 cases and in 2014 was 21.908 cases. The number of hypertension case was high, therefore it caused hypertension was included as top ten prevalence disease in Pamekasan District on 2012-2014. This research aimed to know the economic burden of hypertension patient with Insurance Fee Waiver of National Health Insurance status in Pamekasan District. This research was a quantitative and observational research with cross sectional approach. The sampling was done using a purposive sampling. Primary data collection techniques was done by interview to 100 respondents with questionnaire to get depth information about some variables in this research. The result showed that hypertension patients with Insurance Fee Waiver of National Health Insurance status was diagnosed on 52 years old with DALYs value is 19.
\end{abstract}


Average Direct costwhich is carried by hypertension people with Insurance Fee Waiver of National Health Insurance status in Pamekasan District is Rp157.600, - andaverage indirect cost is Rp674.980,-. The conclusion of this research is indirect cost is greater than direct cost. There are $65 \%$ respondent that pay health care. It makes economic burden will be greater and there are still many people who do not relize that hypertension will cause economic burden that can also influence welfare on household, regional or national level.

Keywords: Hypertension, Economic Burden, Insurance Fee Waiver

\section{PENDAHULUAN}

Kesehatan merupakan hak dari setiap warga negara sebagimana yang tercantum dalam Undan-Undang Nomor 36 Tahun 2009 tentang Kesehatan. Sejak tahun 2014 lalu pemerintah Indonesia berupaya untuk memenuhi hak setiap warga negara atas kesehatan, dengan merancang sebuah program jaminan sosial di bidang kesehatan yang dikenal dengan Jaminan Kesehatan Nasional (JKN). Antusias masyarakat begitu tinggi, terbukti dengan semakin meningkatnya angka kunjungan ke tempat pelayanan kesehatan. JKN memudahkan masyarakat untuk mendapatkan pelayanan kesehatan tanpa harus membayar secara tunai, terutama mereka yang merupakan peserta PBI di mana pembayaran iuran telah ditanggung pemerintah. Namun, di sisi lain karena kemudahan tersebut masyarakat menjadi mengabaikan upaya promotif dan preventif.

Pamekasan merupakan salah satu kabupaten di Pulau Madura dengan total penduduk pada tahun 2014 sebanyak 839.926 jiwa dengan jumlah penduduk laki-laki sebanyak 407.585 jiwa dan penduduk perempuan sebanyak 432.341 jiwa. Pada tahun 2014 jumlah peserta PBI di Kabupaten Pamekasan sebanyak 463.559 jiwa. Selain itu, perlu diketahui di Kabupaten Pamekasan hipertensi merupakan satu-satunya penyakit kronis yang termasuk dalam kategori 10 penyakit terbesar selama periode 2012 - 2014 dengan rata-rata jumlah kasus yaitu 20.493. Masalah hipertensi yang tidak ditangani dengan baik akan memberikan dampak pada beban ekonomi baik pada masyarakat maupun pemerintah, produktivitas dan komplikasi atau penyakit penyerta.

Tujuan penelitian ini yaitu menghitung nilai biaya langsung dan tidak langsung yang ditanggung serta Disability Adjusted Life Years (DALYs)penderita hipertensi dengan status PBI JKN di Kabupaten Pamekasan. Adapun manfaat penelitian ini yaitu hasil penelitian dapat dijadikan sebagai pertimbangan dalam merencanakan program preventif dan promotif untuk penyakit hipertensi di Kabupaten Pamekasan serta sebagai alat advokasi untuk pembuat kebijakan. Selain itu hasil penelitian juga dapat dijadikan pertimbangan bagi masyarakat untuk senantiasa menerapkan upaya preventif dan promotif dalam kehidupan sehari-hari.

\section{METODE}

Jenis penelitian ini termasuk dalam penelitian kuantitatif dan observasional. Sedangkan ditinjau dari waktu, penelitian ini termasuk penelitian cross sectional, yaitu pengamatan dilakukan sekali dalam saat tertentu saja. Besar sampel pada penelitian in dihitung dengan menggunakan rumus Lemeshow untuk jumlah populasi yang tidak diketahui. Adapun rumus perhitungannya adalah sebagai berikut (Lemeshow, 1997): $\mathrm{n}=\left(\mathrm{Z}^{2} \times \mathrm{P}(1-\mathrm{P})\right) / \mathrm{d}^{2}$

Keterangan:

$\mathrm{n}=$ Jumlah sampel

$\mathrm{z}=$ skor $\mathrm{z}$ pada kepercayaan $95 \%$

$=1,96$

$\mathrm{p}=$ maksimal estimasi $=0,5$

$\mathrm{d}=$ alpha $(0,10)$ atau sampling error $=10 \%$ 
Berdasarkan perhitungan besar sampel dengan menggunakan rumus di atas, maka didapatkan jumlah sampel minimal sebanyak 96,04 = 96 Sehingga pada penelitian ini setidaknya peneneliti harus mengambil data dari sampel sekurangkurangnya sejumlah 97 orang. Namun, pada penelitian ini jumlah responden yang diteliti sebanyak 100 orang. Responden merupakan penderita hipertensi dengan status PBI JKN, di mana telah terdiagnosis hipertensi minimal 1 tahun yang lalu dan minimal pernah tergolong dalam kategori hipertensi stage 1 menurut JNC VII (140 159 / 90 - 99 mmHg) serta tidak ada penyakit penyerta. Teknik yang digunakan dalam pengumpulan data primer adalah melalui wawancara kepada responden dengan menggunakan kuesioner. Data sekunder diperoleh dari Dinas Kesehatan, Puskesmas, BPJS Kesehatan dan atau sumber lain yang mendukung.

\section{HASIL DAN PEMBAHASAN}

\section{Biaya Langsung}

Biaya langsung pada penelitian ini diidentifikasi menjadi biaya perawatan (rawat jalan dan rawat inap) dan biaya pengobatan (rawat jalan dan rawat inap). Biaya perawatan rawat jalan adalah biaya

Tabel 1 Biaya Langsung Pada Penderita Hipertensi dengan Status PBI JKN di Kabupaten Pamekasan

\begin{tabular}{cccc}
\hline $\begin{array}{c}\text { Komponen } \\
\text { Biaya } \\
\text { Langsung }\end{array}$ & \multicolumn{2}{c}{ Pelayanan } & \multirow{2}{*}{ Rawat } \\
\cline { 2 - 3 } & Jalan & $\begin{array}{c}\text { Rawat } \\
\text { Inap }\end{array}$ & Total \\
\hline $\begin{array}{c}\text { Biaya } \\
\text { Perawatan (Rp) }\end{array}$ & 116.340 & 0 & 116.340 \\
\hline $\begin{array}{c}\text { Biaya } \\
\text { Pengobatan } \\
\text { (Rp) }\end{array}$ & 41.560 & 0 & 41.560 \\
\hline Total & 157.600 & 0 & 157.600 \\
\hline
\end{tabular}

Berdasarkan Tabel 1 dapat diketahui bahwa total biaya langsung rawat jalan per tahun adalah sebesar Rp.157.600,-. Menurut hasil analisis statistik deskriptif, diketahui bahwa sebanyak 35\% responden tidak mengeluarkan biaya untuk yang dikeluarkan responden untuk melakukan pemeriksaan rutin setiap tahun. Besar biaya pemeriksaan rutin yang dikeluarkan responden diperoleh dengan mengalikan biaya sekali pemeriksaan dengan frekuensi pemeriksaan selama setahun.

Biaya perawatan rawat inap adalah biaya yang dikeluarkan selama mendapatkan pelayanaan rawat inap. Besar biaya pelayanan rawat inap yang dikeluarkan responden diperoleh dari biaya sekali pelayanan rawat inap selama periode tertentu dikalikan dengan frekuensi pelayanan rawat inap yang didapatkan responden.

Biaya pengobatan dalam penelitian ini dibagi menjadi pengobatan rawat jalan (pengobatan medis dan non medis) dan pengobatan medis rawat inap. Besar biaya pengobatan rawat jalan yang dikeluarkan responden diperoleh dari biaya sekali pengobatan dikalikan dengan frekuensi pengobatan selama setahun. Adapun besar biaya pengobatan rawat inap yang dikeluarkan responden diperoleh dari biaya sekali pengobatan dikalikan dengan frekuensi rawat inap. Tabel di bawah ini merupakan biaya langsung yang dikeluarkan penderita hipertensi dengan status PBI JKN di Kabupaten Pamekasan: melakukan pemeriksaan rutin. Sedangkan $65 \%$ lainnya masih mengeluarkan biaya pemeriksaan rutin dengan tarif dan frekuensi yang bervariasi, meski mereka adalah peserta PBI JKN.Biaya perawatan rawat jalan yang dikeluarkan oleh responden digunakan untuk membayar jasa pelayanan dan obat-obatan yang diperoleh saat melakukan pemeriksaan rutin.Responden masih mengeluarkan biaya saat melakukan pemeriksaan rutin karena tidak

memanfaatkan status kepesertaan JKN yang dimiliki.

Menurut hasil penelitian diketahui sebanyak $11 \%$ dari total responden pernah mendapatkan pelayanan rawat inap dengan diagnosa hipertensi dan dengan frekuensi 
rawat inap yang bervariasi. Penderita hipertensi dengan status PBI di Kabupaten Pamekasan yang pernah dirawat inap tidak mengeluarkan biaya dalam mendapatkan pelayanan rawat inap.

Berdasarkan Tabel 1 dapat diketahui bahwa biaya pengobatan (baik medis maupun non medis) rawat jalan per tahun pada penderita hipertensi dengan status PBI JKN sebesar Rp41.560,-. Selain itu, menurut hasil penelitian diketahui bahwa 98\% responden tidak mengeluarkan biaya untuk mendapatkan pengobatan medis. Hal tersebut dikarenakan tarif yang dibayar oleh sebagian besar responden saat melakukan pemeriksaan rutin sudah termasuk biaya obat-obatan. Perlu diketahui juga bahwa $61 \%$ responden tidak mengeluarkan biaya pengobatan non medis selama menderita hipertensi.

Biaya pengobatan medis digunakan untuk membeli obat di apotek, tanpa pergi ke pelayanan kesehatan terlebih dahulu. Adapun biaya pengobatan non medis digunakan untuk membeli obat tradisional yang dipercaya dapat menurunkan tekanan darah.Namun, tidak ada responden yang mengeluarkan biaya untuk pengobatan selama mendapatkan pelayanan rawat inap. Dengan demikian dapat disimpulkan bahwa seluruh responden telah memanfaatkan kartu peserta PBI JKN dalam mendapatkan pengobatan rawat inap.

Penerima Bantuan Iuran (PBI) merupakan salah satu kepesertaan JKN yang diperuntukkan bagi masyarakat yang tergolong fakir miskin dan orang tidak mampu, dimana iuran ditanggung oleh pemerintah. Berdasarkan PP Nomor 19 Tahun 2016 tentang tentang Perubahan Kedua Atas Peraturan Presiden. Nomor 12 Tahun 2013Jaminan Kesehatan Pasal 16A ayat 1, iuran Jaminan Kesehatan bagi Peserta PBI Jaminan Kesehatan serta penduduk yangdidaftarkan oleh Pemerintah Daerah sebesar Rp23.000,- per orangper bulan, dimana manfaat akomodasi berupa pelayanan rawat inap yang didapat adalah ruang perawatan kelas
III. Selain itu, peserta PBI tidak diperkenankan untuk mengajukan peningkatan kelas perawatan dalam memperoleh pelayanan rawat inap.

Selain itu, pemerintah juga telah mengatur dan menjelaskan tentang manfaat yang didapat oleh peserta $\mathrm{JKN}$, termasuk peserta PBI sebagaimana telah diatur dalam PMK Nomor 28 Tahun 2013 tentang Pedoman Pelaksanaan Program Jaminan Kesehatan Nasional. Dalam peraturan tersebut telah dijelaskan bahwa manfaat Jaminan Kesehatan Nasional terdiri atas dua jenis, yaitu manfaat medis dan manfaat non-medis. Manfaat medis Jaminan Kesehatan Nasional berupa pelayanan kesehatan yang komprehensif dan mencakup promotif, preventif, kuratif, dan rehabilitatif sesuai dengan indikasi medis yang tidak terikat dengan besaran iuran yang dibayarkan, termasuk pelayanan obat dan bahan medis habis pakai sesuai dengan kebutuhan medis. Sedangkan manfaat non-medis meliputi akomodasi dan ambulan.

Berdasarkan hasil observasi dan wawancara yang dilakukan baik dengan responden maupun dengan petugas puskesmas setempat, diketahui beberapa alasan yang mendasari masyarakat tidak memanfaatkan status kepesertaan PBI JKN:

1. Masyarakat masih belum mengetahui fungsi dan manfaat kartu peserta;

2. Masyarakat lebih memilih untuk periksa ke provider yang belum bekerja sama dengan BPJS karena berkaitan dengan kefektivitaas pemeriksaan dan pengobatan dari provider tersebut;

3. Masyarakat berparadigma bahwa kualitas pelayanan dan pengobatan untuk pasien umum lebih baik daripada pasien BPJS;

4. Masyarakat sering merasa sungkan kepada provider apabila datang berobat tetapi tidak ada biaya atas pelayanan yang telah diberikan.

5. Masyarakat merasa malu jika periksa dan berobat ke provider dengan 
menggunakan kartu peserta dengan status PBI.

Berdasarkan kelima alasan di atas dapat disimpulkan bahwa informasi mengenai Jaminan Kesehatan Nasional belum merata di semua wilayah di Kabupaten Pamekasan. Oleh karena itu, meski program Jaminan Kesehatan Nasional (JKN) telah berjalan selama dua tahun, Badan Penyelenggara Jaminan Sosial (BPJS) perlu bekerja sama dengan Dinas Kesehatan dan Puskesmas dalam melakukan sosialisasi secara menyeluruh kepada masyarakat tentang program Jaminan Kesehatan Nasional (JKN), termasuk manfaat apa saja yang diperoleh bagi peserta JKN. Sehingga diharapakan informasi dapat tersebar secara merata di seluruh lapisan masyarakat dan masyarakat dapat memanfaatkan status kepesertaan mereka dengan baik.

Selain itu, Dinas Kesehatan Kabupaten Pamekasan perlu melakukan evaluasi mengenai pemanfaatan status peserta JKN, terutama peserta PBI. Pelaksanaan evaluasi membutuhkan data yang akurat, dimana data tersebut bisa diperoleh dari laporan kunjungan pasien baik di FKTP maupun FKTL. Oleh karena itu, FKTP dan FKTL harus melakukan pencatatan dan pelaporan yang baik dan tepat waktu. Dinas Kesehatan Kabupaten Pamekasan juga perlu melakukan pendekatan kepada fasilitas kesehatan baik tingkat pertama maupun lanjutan agar dapat bekerja sama dengan BPJS dalam memberikan pelayanan kesehatan kepada masyarakat. Semakin banyak faskes yang bekerja sama dengan BPJS, masyarakat akan lebih leluasa memilih fasilitas kesehatan sesuai dengan apa yang diharapkan.

\section{Biaya Tidak langsung}

Pada penelitian ini biaya tidak langsung diidentifikasi menjadi biaya productivity loss (rawat jalan dan rawat inap), alat bantu, transportasi (rawat jalan dan rawat inap) dan pendamping (rawat jalan dan rawat inap). Tabel di bawah ini merupakan biaya tidak langsung yang dilkeluarkan penderita hipertensi dengan satatus PBI JKN di Kabupaten Pamekasan:

Tabel 2 Biaya Tidak Langsung pada

Penderita Hipertensi dengan Status PBI JKN di Kabupaten Pamekasan

\begin{tabular}{cccc}
\hline Komponen & \multicolumn{2}{c}{ Pelayanan } & Total \\
\cline { 2 - 3 } $\begin{array}{c}\text { Biaya Tidak } \\
\text { Langsung }\end{array}$ & $\begin{array}{c}\text { Rawat } \\
\text { Jalan }\end{array}$ & $\begin{array}{c}\text { Rawat } \\
\text { Inap }\end{array}$ & \\
\hline $\begin{array}{c}\text { Biaya } \\
\text { Productivity } \\
\text { loss (Rp) }\end{array}$ & 480.600 & 12.727 & 493.327 \\
\hline $\begin{array}{c}\text { Biaya Alat } \\
\text { Bantu (Rp) }\end{array}$ & 0 & 0 & 0 \\
\hline $\begin{array}{c}\text { Biaya } \\
\text { Transportasi } \\
\text { (Rp) }\end{array}$ & 41.290 & 104.818 & 146.108 \\
\hline $\begin{array}{c}\text { Biaya } \\
\text { Pendamping } \\
\text { (Rp) }\end{array}$ & 6.000 & 29.545 & 35.545 \\
\hline Total & 527.890 & 147.090 & 674.980 \\
\hline
\end{tabular}

Berdasarkan Tabel 2 dapat diketahui bahwa rata-rata biaya tidak langsung rawat jalan per tahun yang dikeluarkan sebesar Rp. 527.890,- dan rawat inap sebesar Rp.147.090,-. Sebagian besar responden tidak mengeluarkan biaya productivity loss baik rawat jalan maupun rawat inap. Hal tersebut kemungkinan dikarenakan beberapa hal. Pertama, manifestasi klinis hipertensi (seperti telinga berdenging, sukar tidur, sesak nafas, rasa berat ditekuk, mudah lelah, sakit kepala, dan mata berkunang-kunang) yang dialami oleh penderita hipertensi sering kali diabaikan karena dianggap tidak terlalu memberatkan dan menghalangi pekerjaan. Sehingga, sebagian besar penderita hipertensi biasanya tetap bekerja meski merasakan manifestasi klinis hipertensi supaya dapat menghidupi keluarga. Kedua, mayoritas responden tidak bekerja. Sehingga tidak ada biaya produktivitas yang hilang karena tidak mengalami absensi kerja. Begitu pula pada responden yang pernah dirawat inap, 10 dari 11 orang responden yang pernah dirawat inap atas indikasi hipertensi tidak bekerja. 
Selain itu, seluruh responden tidak mengeluarkan biaya alat bantu. Hal tersebut dikarenakan manifestasi klinis hipertensi tidak menyebabkan penderitanya mengalami keterbatasan dalam beraktivitas. Sehingga, penderita hipertensi tanpa penyakit penyerta masih bisa beraktivitas tanpa bantuan alat bantu. Pada komponen biaya transportasi, terdapat perbedaan yang signifikan antara biaya transportasi rawat jalan dan rawat inap.

Berdasarkan hasil penelitian, diketahui bahwa biaya transportasi rawat inap jauh lebih besar daripada biaya transportasi rawat jalan. Hal tersebut dikarenakan sebagian besar responden tidak mengeluarkan biaya dalam mendapatkan pelayanan rawat jalan ke faskes tujuan, karena jarak antara rumah dan faskes tujuan yang dapat ditempuh dengan jalan kaki atau dengan mengendarai sepeda motor. Bagi responden yang mengendarai sepeda motor, peneliti mengasumsikan bahwa biaya transportasi untuk pergi ke faskes tujuan setara dengan harga 1 liter bahan bakar bersubsidi, yaitu sebesar Rp6.500,-. Beberapa responden juga tidak mengeluarkan biaya transportasi karena provider datang ke rumah responden. Berdasarkan hasil wawancara, responden harus menggunakan kendaraan roda empat untuk menuju faskes tujuan dalam mendapatkan pelayanan rawat inap. Sehingga, responden harus menyewa kendaraan roda empat agar dapat menuju faskes tujuan. Oleh karena itu, biaya transportasi rawat inap lebih besar jika dibandingkan dengan transportasi rawat jalan.

Biaya pendamping merupakan biaya yang dikeluarkan jika penderita membutuhkan jasa pengantar atau pendamping selama sakit. Biaya pendamping terdiri dari honor pengantar atau pendamping dan biaya productivity loss pengantar atau pendamping. Berdasarkan hasil penelitian diketahui bahwa hanya 1 orang responden yang membutuhkan jasa pendamping dalam sehari-hari. Sedangkan 99 orang responden lainnya tidak membutuhkan jasa pendamping. Hal ini dikarenakan manifestasi klinis hipertensi tidak menyebabkan penderitanya mengalami ketergantungan terhadap jasa pendamping dalam melakukan aktivitas sehari-hari.

Pada kasus penderita hipertensi yang pernah dirawat inap, jasa pendamping tentu dibutuhkan saat mendapatkan pelayanan rawat inap baik di FKTP maupun FKTL. Menurut hasil penelitian rata-rata biaya pendamping rawat jalan per tahun yaitu Rp29.545,-. Hasil tersebut diperoleh dari besarnya biaya produktivitas yang hilang karena mendampingi penderita hipertensi. Namun, tidak ada upah untuk membayar jasa pendamping tersebut. Hal ini dikarenakan orang yang mendampingi selama penderita/pasien dirawat inap adalah keluarga penderita/pasien.

Sehingga, dapat disimpulkan bahwa biaya tidak langsung yang dikeluarkan oleh penderita hipertensi dengan status PBI JKN di Kabupaten Pamekasan lebih besar jika dibandingkan dengan biaya langsung. Namun, faktanya masih banyak masyarakat yang belum menyadari bahwa hipertensi yang dialami menyebabkan kerugian ekonomi yang secara tidak langsung juga akan mempengaruhi kesejahteran baik di tingkat rumah tangga, regional maupun nasional.

Menurut Abegunde and Stanciole (2006) jika ditinjau dari perspektif individu atau rumah tangga, kejadian penyakit kronis secara langsung akan menurunkan jumlah angkatan kerja yang disebabkan tingginya angka kematian, absensi kerja, disabilitas dan pensiun dini. Hal tersebut dapat menimbulkan dampak lain, di antaranya angka ketergantungan semakin tinggi, produktivitas menurun, peningkatan konsumsi barang dan pelayanan bidang kesehatan dan mengurangi kemampuan menabung dan investasi. Dampak lain yang timbul jika ditinjau dari perspektif negara yaitu penurunan angka pendapatan per kapita dan angka harapan hidup yang dapat menyebabkan angka pertumbuhan 
ekonomi dan kesejahteraan rendah serta terjadinya kemiskinan. Sehingga, pada jangka waktu yang panjang akan menghambat investasi asing di negara.

Begitu pula dampak yang akan terjadi jika angka prevalensi hipertensi di Kabupaten Pamekasan tidak dikendalikan. Pada tingkat individu atau rumah tangga, hipertensi akan menurunkan tingkat produktivitas yang menyebabkan ketidakstabilan ekonomi masyarakat Kabupaten Pamekasan. Adapun pada tingkat kabupaten akan menyebabkan kesejahteraan dan pertumbuhan ekonomi rendah. Oleh karena itu, Dinas Kesehatan Kabupaten Pamekasan perlu melakukan sebuah upaya untuk menyadarkan masyarakat bahwa hipertensi merupakan penyakit yang berbahaya apabila tidak dikontrol dengan baik dan dapat menyebabkan kerugian ekonomi yang besar.

\section{Disability Adjusted Life Years (DALYs)}

Disability-Adjusted Life Years (DALYs) adalah perbedaan antara situasi saat ini dan situasi yang ideal di mana setiap orang hidup sampai usia harapan hidup standar, dan dalam kondisi kesehatan yang sempurna atau dengan sederhana DALYs merupakan jumlah tahun yang hilang akibat seseorang sakit. Pada penelitian ini, umur harapan hidup diperoleh dari hasil sensus penduduk 2010 yang diproyeksi dengan menggunakan aplikasi spectrum. Hasil proyeksi tersebut menunjukkan bahwa umur harapan hidup masyarakat Kabupaten Pamekasan pada tahun 2016 adalah 71 tahun. Rata-rata umur mulai sakit pada penderita hipertensi dengan status PBI JKN di Kabupaten Pamekasan dengan berdasar pada hasil penelitian yaitu 52 tahun.

Variabel umur mulai sakit sangat menentukan nilai Disability Adjusted Life Years (DALYs). Umur mulai sakit berbanding terbalik dengan nilai Disability Adjusted Life Years (DALYs). Artinya, semakin muda umur mulai sakit, semakin tinggi nilai Disability Adjusted Life Years (DALYs). Berikut ini adalah rumus dan perhitungan nilai DALYs berdasarkan Rochmah (2014) pada penderita hipertensi dengan status PBI JKN di Kabupaten Pamekasan:

DALYs = UHH - rata-rata umur mulai sakit

$=71-52$

$=19$

Keterangan:

DALYs= Disability Adjusted Life Years

UHH= Umur Harapan Hidup

Berdasarkan perhitungan di atas dapat disimpulkan bahwa jumlah tahun yang hilang akibat disabilitas pada penderita hipertensi dengan status PBI JKN di Kabupaten Pamekasan adalah 19 tahun.

\section{SIMPULAN}

1. Rata-rata biaya langsung rawat jalan yang dikeluarkan oleh penderita hipertensi dengan status PBI JKN di Kabupaten Pamekasan yaitu sebesar Rp157.600,- dengan rincian biaya langsung rawat jalan per tahun sebesar Rp157.600,-. dan biaya langsung rawat inap sebesar Rp0,-.

2. Rata-rata biaya tidak langsung (terdiri dari biaya productivity loss, alat bantu, transportasi dan pendamping) yang dikeluarkan oleh penderita hipertensi dengan status PBI JKN di Kabupaten Pamekasan sebesar Rp674.980,- dengan rincian biaya tidak langsung rawat jalan per tahunsebesar Rp527.890,- danbiaya tidak langsung rawat inap sebesar Rp147.090,--

3. Disability Adjusted Life Years (DALYs) atau jumlah tahun yang hilang akibat disabilitas pada penderita hipertensi dengan status PBI JKN di Kabupaten Pamekasan adalah 19 tahun. 


\section{Bagi Dinas Kesehatan Kabupaten Pamekasan}

1. Mendayagunakan provider pelayanan kesehatan yang telah bekerjasama dengan BPJS untuk melakukan sosialisai kepada peserta JKN baik PBI dan non PBI yang menjadi tanggsung jawabnya, mengenai manfaat apa saja yang diperoleh bagi peserta JKN. Sehingga masyarakat peserta JKN dapat memanfaatkan status kepesertaan merekadengan baik.

2. Melakukan pendekatan kepada fasilitas kesehatan baik tingkat pertama maupun lanjutan agar dapat bekerja sama dengan BPJS dalam memberikan pelayanan kesehatan kepada masyarakat. Semakin banyak faskes yang bekerja sama dengan BPJS, masyarakat lebih leluasa memilih fasilitas kesehatan sesuai dengan apa yang diharapkan dalam mendapatkan pelayanan kesehatan.

3. Menghimbau seluruh fasilitas kesehatan yang telah bekerjasama dengan BPJS untuk melakukan dan melaporkan survei rutin kepuasan pasien BPJS. Selanjutnya Dinas Kesehatan Kabupaten Pamekasan melakukan evaluasi secara berkala dengan menggunakan laporan kepuasan pasien BPJS sebagai dasar pelaksanaan evaluasi dan memberikan umpan balik kepada FKTP dan FKTL sesuai dengan hasil evaluasi.

\section{Bagi Puskesmas}

1. Melakukan upaya promotif kepada masyarakat bahwa pelayanan kesehatan termasuk jenis obat yang diberikan kepada pasien BPJS baik di FKTP maupun FKTL telah disesuaikan dengan standar yang telah ditetapkan.

2. Merancang sebuah upaya promotif untuk menyadarkan masyarakat, khususnya peserta PBI JKN bahwa hipertensi merupakan penyakit yang berbahaya apabila tidak dikontrol dengan baik dan dapat menyebabkan kerugian ekonomi yang besar serta mempengaruhi kesejahteraan baik di tingkat rumah tangga, regional maupun nasional. Upaya yang dimaksud dapat dilakukan baik dengan menggunakan media visual, audio maupun audiovisual yang disesuaikan dengan karakteristik masyarakat setempat.

\section{DAFTAR PUSTAKA}

Abegunde, D and Stanciole, A. 2006. Working Paper WHO: An Estimation of The Economic Impact of Chronic Noncommunicable Diseases In Selected Countries [pdf] Tersediadi(http://www.who.int/chp/ working_paper_growth\%20model29 may.pdf) Diakses tanggal $28 \mathrm{Mei}$ 2016.

Badan Pusat Statistik. 2010. Sensus Penduduk Tahun 2010. [pdf] Jakarta: Badan Pusat Statistik. Tersedia di (http://sp2010.bps.go.id/) Diakses Tanggal 21 April 2016.

Bonita R., Beaglehole R., Kjellstrom T. 2006. Basic Epidemiology. 2nd edition. Switzerland: WHO Press.

Dinas Kesehatan Kabupaten Pamekasan. 2014. Profil Kesehatan Kabupaten Pamekasan Tahun 2014. Pamekasan: Dinas Kesehatan.

Lemeshow, Stanley., 1997, Besar Sampel dalam Penelitian Kesehatan, Universitas Gadjah Mada: Yogyakarta.

Peraturan Pemerintah Nomor 19 Tahun 2016 tentang tentang Perubahan Kedua Atas Peraturan Presiden. Nomor 12 Tahun 2013 Jaminan Kesehatan. Jakarta: Republik Indonesia.

Peraturan Pemerintah Republik Indonesia Nomor 76 Tahun 2015 tentang Perubahan Atas Peraturan Pemerintah Nomor 101 Tahun 2012 tentang Penerima Bantuan Iuran Jaminan. Jakarta: Republik Indonesia.

Peraturan Menteri Kesehatan Nomor 28 Tahun 2013 tentang Pedoman 
Pelaksanaan Program Jaminan

Kesehatan Nasional. Jakarta:

Republik Indonesia .

Undang - Undang Nomor 36 Tahun 2009 tentang Kesehatan. Jakarta: Republik Indonesia.

WHO. 2009. The Global Burden of Disease Concept. [pdf] Tersedia di (http://www.who.int/quantifying_ehi mpacts/publications/en/9241546204 chap3.pdf.) Diakses tanggal 21 Oktober 2015. 